\title{
Evolution and palaeoecology of early turtles: a review based on recent discoveries in the Middle Jurassic
}

\author{
Jérémy Anquetin ${ }^{1 *}$
}

1UMR CNRS 7207 MNHN UPMC, Muséum National d'Histoire Naturelle, Département Histoire de la Terre, 75231 Paris, France

*Corresponding author: jeremy.anquetin@jurassica.ch

\begin{abstract}
In recent years, no less than five new species of stem-group turtles have been described worldwide. Among them are three new turtles from Middle Jurassic deposits that partially fill a previous temporal and morphological gap in our knowledge of the early evolution of these shelled amniotes: Heckerochelys romani, Condorchelys antiqua and Eileanchelys waldmani. For the first time, the phylogenetic position of these three new species is tested in the context of the two presently competing cladistic models of turtle evolution. The addition of these taxa to each matrix does not favour or alter any of the two opposed hypotheses. However, it is demonstrated here that, by documenting yet unknown stages in the evolution of several morphological structures, these three species give stronger support to the model of an extended phylogenetic stem for turtles. These new lines of evidence include the structure of the vomer, the position of the aditus canalis stapedio-temporalis and of the posterior opening of the canalis cavernosus, and the morphology of the processus interfenestralis of the opisthotic. These characters should be considered for future phylogenetic analyses of turtle interrelationships.
\end{abstract}

Recent discoveries also reinvigorate the debate about the palaeoecology of early turtles. Whereas simple morphological characters (e.g., shell fontanelle, ligamentous bridge, flattened carapace) can be misleading, forelimb proportions and shell bone histology have led to the conclusion that most stem turtles (i.e., Proganochelys quenstedti, Palaeochersis talampayensis, Proterochersis robusta, Kayentachelys aprix and meiolaniids) were terrestrial forms. On the contrary, it is generally accepted that crown-group turtles are ancestrally aquatic. Among the five recently described stem-group turtles, Odontochelys semitestacea and Eileanchelys waldmani have been convincingly interpreted as having aquatic habits, which suggests that basal turtles were ecologically diverse. More investigation is needed, but this will undoubtedly trigger further debate on the primitive ecology of turtles and on the origin of aquatic habits in Testudines (i.e., the crown-group), respectively. 


\section{INTRODUCTION}

Knowledge of early turtles has improved dramatically in recent years due to the discovery of rich and relatively well preserved material. Since 2006, no less than five new species have been described from a time period extending from the Carnian (Late Triassic; circa $220 \mathrm{Ma}$ ) to the Bathonian (Middle Jurassic; circa $165 \mathrm{Ma}$ ). Previously, only seven species were known from the same period and represented by sufficiently preserved material (i.e., Proganochelys quenstedti, Proterochersis robusta, Palaeochersis talampayensis, Australochelys africanus, Kayentachelys aprix, Indochelys spatulata, and Siamochelys peninsularis). Among the five recently discovered taxa, two are from the Late Triassic: Odontochelys semitestacea Li et al., 2008 from the Carnian of southwestern China, and Chinlechelys tenertesta Joyce et al., 2009 from the Norian of New Mexico. The latter is known by relatively scarce material but the neck spine recalling those of Proganochelys quenstedti and the anteroposteriorly compressed dorsal ribs are enough to support a very basal position in the turtle phylogenetic tree [Joyce et al., 2009].

Odontochelys semitestacea is probably the most widely publicized of these recently discovered early turtles, not only because it has been heralded the oldest turtle known to date. Represented by at least two complete individuals, this is the only stem turtle that possesses teeth in the upper and lower jaws and is therefore considered the most primitive unambiguous stem turtle. Odontochelys semitestacea is also characterised by the presence of a complete plastron but not of an ossified carapace, with the exception of neural plates [Li et al., 2008]. Although an alternative interpretation involving paedomorphosis exists [Reisz and Head, 2008], Li et al. [2008] concluded that $O$. semitestacea documents an intermediate step in the evolution of the turtle shell, hence favouring the de novo model for the origin of the shell [see Gilbert et al., 2001; Cebra-Thomas et al., 2005; Joyce et al., 2009]. Yet, as pointed out by Lyson and Gilbert [2009], this discovery generates more questions than it actually answers for the moment. Chinlechelys tenertesta and Odontochelys semitestacea are not further discussed herein, because of the scarce nature of the material and of the lack of published, detailed morphological description, respectively.

The three remaining recently discovered early turtles were all found in Middle Jurassic deposits: Heckerochelys romani Sukhanov, 2006 from Russia (no later than Bathonian); Condorchelys antiqua Sterli, 2008 from Argentina (Middle Jurassic); and Eileanchelys waldmani Anquetin et al., 2009 from Scotland (Bathonian). These three species are known from associated cranial and postcranial material of several individuals. Previously, the turtle fossil record was relatively scarce in the Middle Jurassic, being limited mainly to poorly known shell material from Asia and fragmentary remains from England [Ye, 1994; Tong et al., 2002; Anquetin and Claude, 2008; Danilov and Parham, 2008; Scheyer and Anquetin, 2008; Rabi et al., 2010]. The three recently described species document yet unknown stages in the evolution of early turtles and partly bridge the morphological gap that existed between Early Jurassic forms, such as Kayentachelys aprix, and Late Jurassic taxa. The purpose of the present paper is to review how these three new Middle Jurassic species improve our understanding of early turtle evolution and palaeoecology.

\section{MATERIAL AND METHODS}

Unless otherwise stated, references for species in the following discussion are: Sukhanov [2006] for Heckerochelys romani; Sterli [2008] and Sterli and de la Fuente [2010] for Condorchelys antiqua; Anquetin et al. [2009] and Anquetin [in press] for Eileanchelys waldmani; Sterli and Joyce [2007], Gaffney and Jenkins [2010], and personal observation of material available to both previous studies for Kayentachelys aprix. This paper follows Zangerl [1969] for the nomenclature of shell elements, Gaffney $[1972,1979]$ for the nomenclature of the skull anatomy, and Joyce et al. [2004] for the phylogenetic definition of clade names for turtles.

Heckerochelys romani, Condorchelys antiqua and Eileanchelys waldmani were included in the data matrices of Gaffney et al. [2007] and Joyce [2007] (see Appendix 1); 28 taxa coded for 111 characters, and 68 taxa coded for 136 characters, respectively. Both matrices were assembled with MacClade 4.01 [Maddison and Maddison, 2001] and analysed using PAUP 4.0b10 [Swofford, 2002]. Gaffney et al. [2007] did not specify which parameters they used to run their analysis; however, similar results were reproduced with the following settings: 'Synapsida/ Diapsida' as outgroup; characters unordered, reversible and equally-weighted; multistate taxa treated as uncertainty. The matrix of Joyce [2007] was analysed using the author's original settings and following the procedure of his third analysis [ibid., pp. 7, 52]. For both matrices, the most parsimonious solution was sought using heuristic algorithms with 1,000 randomly seeded replications and tree bisection-reconnection (TBR) swapping algorithm. 

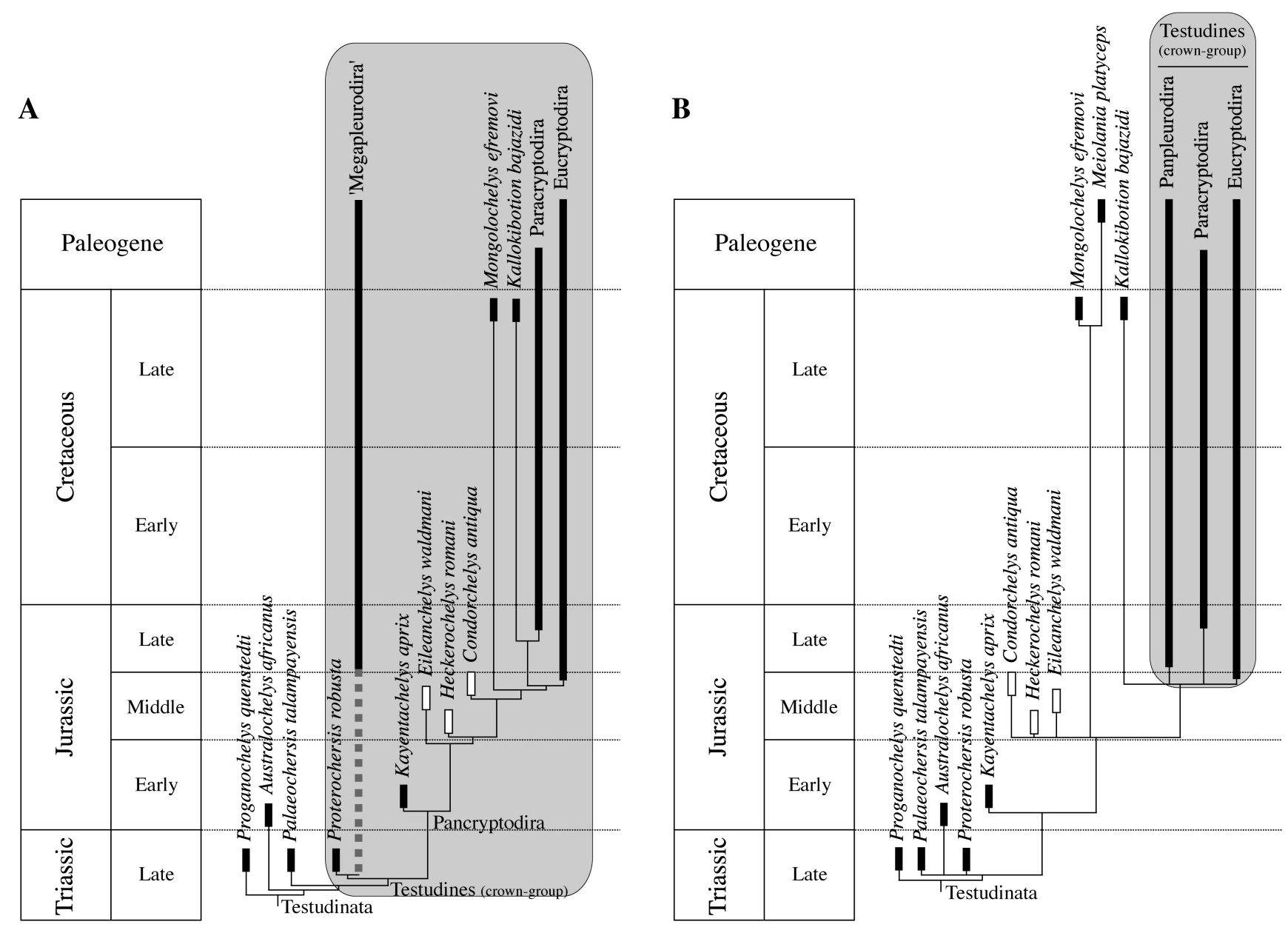

Figure 1 - Phylogenetic relationships of Heckerochelys romani, Condorchelys antiqua and Eileanchelys waldmani. A, strict consensus tree ( 235 steps; $\mathrm{Cl}=0.5447 ; \mathrm{RI}=0.7384)$, amended matrix of Gaffney et al. [2007]; $\mathrm{B}$, strict consensus tree $(510$ steps; $\mathrm{Cl}=$ 0.3314; RI = 0.6810), amended matrix of Joyce [2007]. Grey box represents Testudines (i.e., crown-group turtles). Dashed grey line indicates the extensive ghost lineage of panpleurodires in the context of the hypothesis of Gaffney et al. [2007].

\section{RELATIONSHIPS OF EARLY TURTLES}

\section{Phylogenetic relationships}

For more than thirty years, the cladistic work of E. S. Gaffney and collaborators has supported the hypothesis of an early divergence between Panpleurodira and Pancryptodira during the Late Triassic. As exemplified by their latest contribution [Gaffney et al., 2007], only three species are considered to be stem turtles: Proganochelys quenstedti, Palaeochersis talampayensis and Australochelys africanus. Following this hypothesis, Proterochersis robusta from the Late Triassic of Germany is the most basal panpleurodire, whereas Kayentachelys aprix from the Early Jurassic of Arizona, USA, is the most basal pancryptodire. This implies significant gaps in the fossil record between these two species and the next representative of their respective group: circa 50 m.y. for panpleurodires (from Norian to Oxfordian) and approximately 20 to 30 m.y. for pancryptodires (from Early Jurassic to Bathonian). Given the plesiomorphic nature of Kayentachelys aprix for several characters, a placement of this species as a basal pancryptodire implies a convergent evolution of many features in both panpleurodires and pancryptodires: e.g., closure of the interpterygoid vacuity; loss of pterygoid teeth; reduction of the number of peripheral plates to 11 ; loss of supramarginal scales; loss of the epiplastral processes (= cleithra according to Joyce et al. [2006]).

This long-standing version of early turtle interrelationships was challenged recently by several morphological arguments. The assignment of Proterochersis robusta to panpleurodires is only based on the putative presence of a pelvis fused to the shell in this species. However, Sterli et al. [2007] confirmed the presence of this condition in Palaeochersis talampayensis, an undisputed stem turtle that clearly shares no relationship with panpleurodires, rendering the generally accepted phylogenetic position of Proterochersis robusta questionable. This was already argued by Rougier et al. 
[1995]. The assignment of Kayentachelys aprix to pancryptodires by Gaffney et al. [1987] was also seriously questioned by a thorough redescription of the cranial material. According to Sterli and Joyce [2007], the main characteristics used by Gaffney et al. [1987] to support this assignment (i.e., presence of a processus trochlearis oticum and of a vertical plate on the processus pterygoideus externus) are actually absent in Kayentachelys aprix. These conclusions have been rejected recently by Gaffney and Jenkins [2010], but the latter contribution simply illustrates the fact that the argument over the anatomy of $K$. aprix mainly rests on divergence of interpretation and difference in primary homology assessments. Having studied the concerned material firsthand, I feel more confident with Sterli and Joyce's [2007] study.

The aforementioned morphological observations support the conclusions of the cladistic analysis of Joyce [2007], which represent the most comprehensive morphological analysis of turtle interrelationships so far. In contrast to previous analyses, this study only used species as terminal taxa, which represents a significant improvement. According to Joyce [2007], Proterochersis robusta and Kayentachelys aprix, as well as Mongolochelys efremovi, Meiolania platyceps and Kallokibotion bajazidi, are more basal than the dichotomy between panpleurodires and pancryptodires, which occurs in the Middle Jurassic following these results. Actually, the two aforementioned hypotheses are not so divergent and the main disagreement concern the position of the panpleurodires relatively to other turtles. Following Joyce [2007], the panpleurodires are placed higher in the tree as the sistergroup of the clade uniting Paracryptodira and Eucryptodira (excluding Meiolaniidae) rather than closely related to Proterochersis robusta, which allows reducing significantly the number of convergent evolutions of character within panpleurodires and pancryptodires.

In this context, the recent discovery of three new Middle Jurassic species is particularly important. For the first time, each of these new species was scored for the original matrices of Gaffney et al. [2007] and Joyce [2007]. This was made possible owing to the recently published detailed descriptions of Condorchelys antiqua and Eileanchelys waldmani [Sterli and de la Fuente, 2010; Anquetin, in press]. The analysis of the Gaffney et al.'s [2007] matrix resulted in four equally parsimonious solutions (229 steps; Consistency Index = 0.5590; Retention Index $=0.7531)$. The strict consensus tree (235 steps; $\mathrm{Cl}=0.5447 ; \mathrm{RI}=0.7384$ ) is presented in figure $1 \mathrm{~A}$. The three added species are intercalated between Kayentachelys aprix and Mongolochelys efremovi, with Eileanchelys waldmani as the most basal of the three and Condorchelys antiqua as the most derived. This relative position of the three Middle Jurassic species is in contradiction with available evidence, which suggests that C. antiqua is morphologically similar to K. aprix [Sterli and de la Fuente, 2010] whereas E. waldmani appears more derived by several features [Anquetin, in press]. The analysis of the matrix of Joyce [2007] resulted in 439 equally parsimonious trees (361 steps; $\mathrm{Cl}=0.4681 ; \mathrm{RI}=$ 0.8204). Similarly to results obtained by Joyce [2007], the resolution of the strict consensus tree (510 steps; $\mathrm{Cl}=$ $0.3314 ; \mathrm{RI}=0.6810$; fig. $1 \mathrm{~B}$ ) is relatively low. The relationships between Heckerochelys romani, Condorchelys antiqua and Eileanchelys waldmani are not resolved and these turtles form a polytomy with the clade composed of Meiolania platyceps + Mongolochelys efremovi and a large clade uniting Kallokibotion bajazidi, Panpleurodira, Paracryptodira and Eucryptodira (fig. 1B). In both the Adams and majority rule consensus trees (not shown here), the three recently described Middle Jurassic species are placed more basal than Mongolochelys efremovi and Meiolania platyceps.

These results show that: (1) the inclusion of the three recently described Middle Jurassic taxa does not alter the outcome of either Gaffney et al. [2007] or Joyce [2007]; (2) in both analyses, the three new species are found to be more derived than Kayentachelys aprix and more basal than Mongolochelys efremovi, Kallokibotion bajazidi and Meiolania platyceps; (3) according to both hypotheses of relationships, these three species fill a major temporal gap between $K$. aprix and remaining related turtles, either pancryptodires or Testudines (i.e., crown-group turtles). As for the original results of Gaffney et al. [2007] and Joyce [2007], the principal difference remains the position of panpleurodires in the tree. The phylogenetic pattern of Joyce [2007] is preferred herein because it implies significantly less convergent apparitions of characters in both panpleurodires and pancryptodires [ibid., pp. 57-61; see also below], and because it is more congruent with the stratigraphic record (not implying a 50 m.y. gap in the early fossil record of panpleurodires; fig. 1A). In the following discussion, Heckerochelys romani, Condorchelys antiqua and Eileanchelys waldmani are considered to be stem turtles (i.e., more basal than panpleurodires and pancryptodires). However, given the results presented above, this discussion can be easily transposed into the phylogenetic context defended by Gaffney et al. [2007], omitting considerations about panpleurodires.

\section{Morphological evolution}

In contrast to other amniotes, the jaw musculature of turtles extends far posteriorly within the fossa temporalis superior and needs to be redirected around the otic capsule by a trochlea [Schumacher, 1954; Gaffney, 1979; Joyce, 2007]. In Pleurodira, the trochlea is formed by a 
large lateral expansion of the pterygoid (the processus trochlearis pterygoidei), while in Cryptodira it is located directly on the anterodorsal margin of the otic region. In many cryptodires, the presence of the trochlea may result in a thickening of the anterior wall of the otic capsule (which may be difficult to assess in fossils), an acute angle between the dorsal and anterior surface of the otic chamber, and sometimes in the development of a protruding process (the processus trochlearis oticum). According to Gaffney [1975], these two jaw closure mechanisms are not homologous and appeared independently in panpleurodires and pancryptodires. Gaffney et al. [1987] and Gaffney and Jenkins [2010] refer Kayentachelys aprix to pancryptodires based partly on the putative presence of a processus trochlearis oticum in this taxon. However, as argued by Sterli and Joyce [2007] (and confirmed by personal observation), a processus trochlearis oticum sensu stricto is absent in $K$. aprix. A thickening of the anterior wall of the otic capsule is present in K. aprix [Gaffney and Jenkins, 2010], but according to Joyce [2007] this suggests that a trochlea mechanism comparable to that of cryptodires (the typical cryptodire mechanism is composed of soft tissue and its presence is therefore difficult to assess in fossils unless a proper processus trochlearis oticum is present) developed early among stem turtles and was subsequently modified in panpleurodires. Then in this context, a trochlea developed on the anterodorsal surface of the otic chamber is not a synapomorphy of pancryptodires, but rather of a more inclusive group.

Similarly to K. aprix, Eileanchelys waldmani, Heckerochelys romani and Condorchelys antiqua all lack a processus trochlearis oticum or roughed area on the anterodorsal surface of the otic region. According to Sterli and de la Fuente [2010], the latter species does have a thickened anterior wall of the otic chamber (condition unknown in $H$. romani and $E$. waldmani). However, considering the importance that Gaffney and Jenkins [2010] give to this feature, a detailed survey of the variation in thickness of the anterior wall of the otic chamber in early turtles (stem turtles, as well as basal panpleurodires and pancryptodires) is necessary before conclusion can be drawn.

Proganochelys quenstedti has been described as lacking a prefrontal-vomer contact [Gaffney, 1990]. Sterli and Joyce [2007, p. 693], citing Gaffney [1990], suggest that this contact was actually probably present in $P$. quenstedti, but as argued by Gaffney and Jenkins [2010], there is currently no support for this statement. A prefrontal-vomer contact has been reported in Kayentachelys aprix, but this area is badly preserved in all specimens and the contact is visible in none [Gaffney et al., 1987; Sterli and Joyce, 2007]. In contrast, a prefrontal- vomer contact is present in Eileanchelys waldmani and Heckerochelys romani [Sukhanov, 2006; Anquetin et al., 2009; Anquetin, in press]. It should be noted here that Anquetin et al. [2009] were incorrect in stating that the vomer is not preserved in available specimens of $H$. romani. Remains of Eileanchelys waldmani (the description of $\mathrm{H}$. romani is not detailed enough and no illustration of the vomer is proposed) document an intermediate stage in the evolution of the typical chelonian vomer [Anquetin et al., 2009, fig. 5]. In basalmost turtles, as exemplified by Proganochelys quenstedti, the vomer, which is still paired, is a flat, dorsally arched element that only has contacts with surrounding bones at its anterior (with premaxilla and maxilla) and posterior (with palatine and pterygoid) margins. Hence, the vomer forms the medial margin of each apertura narium interna and no proper meatus choanae (i.e., internal narial canal) is developed. In the intermediate stage, as exemplified by E. waldmani (and maybe by $H$. romani and $K$. aprix as well), the vomer is a flat, horizontal element that contacts the prefrontal dorsolaterally, but it remains an element free of contact for most of its length. As in $P$. quenstedti, the vomer forms the medial margin of the apertura narium interna and there is no meatus choanae. In all more derived turtles, the vomer is characterised by a three-dimensional morphology with anterior and posterior horizontal portions connected by the sagittal septum (the dumbbell shape of Gaffney [1979]). The sagittal septum separates the two meatus choanae, which are variably developed in concerned turtles, whereas the anterior portion of the vomer participates to the formation of an incipient secondary palate [Anquetin et al., 2009; Anquetin, in press]. In all these turtles, including meiolaniids, Mongolochelys efremovi, Kallokibotion bajazidi, pancryptodires and panpleurodires, the contacts of the vomer with surrounding bones (premaxilla, maxilla, pterygoid and palatine) become significantly more extensive. This is further evidence in favour of Joyce's [2007] hypothesis (fig. 2B), whereas in the context of Gaffney et al. [2007] the three-dimensional morphology of the vomer and these extensive contacts would have to develop independently in both panpleurodires and pancryptodires (fig. 2A). The prefrontal-vomer contact is then secondarily lost in pleurodires (condition unknown in stem pleurodires) and some trionychids, and the vomer is lost altogether in many pelomedusids and in Cycloderma frenatum [Gaffney, 1979; Meylan, 1987].

As argued by Anquetin [in press], Kayentachelys aprix and Eileanchelys waldmani illustrate intermediate stage regarding the morphology of the canalis cavernosus and the position of the aditus canalis stapedio-temporalis. In Proganochelys quenstedti (condition unknown in Odontochelys semitestacea), the basipterygoid articulation 
A

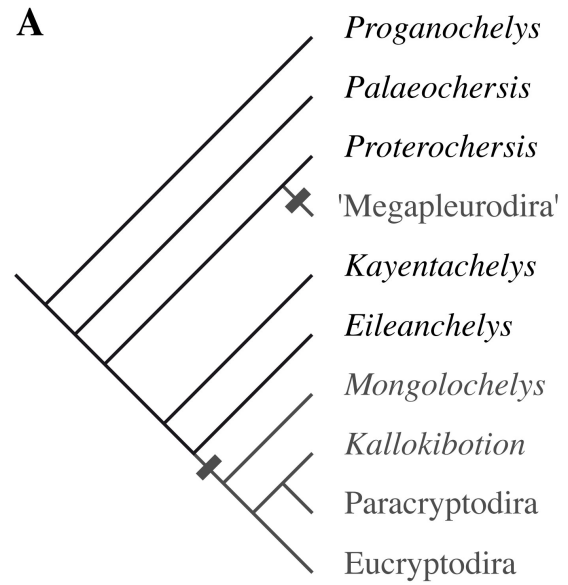

B

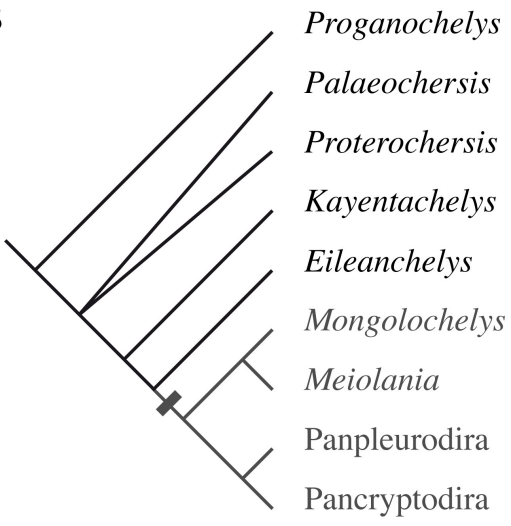

Figure 2-Optimisation (DELTRAN) of the evolution of the typical chelonian vomer. A, simplified strict consensus tree, amended matrix of Gaffney et al. [2007]; B, simplified strict consensus tree, amended matrix of Joyce [2007]. Grey: vomer with a modern morphology (see text).

is still open (absence of canalis cavernosus) and the stapedial artery passes through a slit formed between the processus paroccipitalis of the opisthotic and the quadrate [Gaffney, 1990; fig. 3A]. In Palaeochersis talampayensis and Australochelys africanus, the basipterygoid articulation is fused so that a very short canalis cavernosus is present for the passage of the lateral head vein [Gaffney and Kitching, 1995; Sterli et al., 2007]. The position of the passage for the stapedial artery is indeterminable in these species. In $K$. aprix and $E$. waldmani, the pterygoid extends posteriorly along the basisphenoid and the canalis cavernosus increases in length. The canalis cavernosus is shorter in $K$. aprix than in E. waldmani or Heckerochelys romani [Anquetin, in press]. It appears to be slightly longer in Condorchelys antiqua than in E. waldmani and $H$. romani [Sterli and de la Fuente, 2010, fig. 3A, B]. The aditus canalis stapediotemporalis (the ventral opening of the canalis stapediotemporalis in the roof of the cavum acustico-jugulare) is located at the level of the anterior wall of the fenestra ovalis in K. aprix and E. waldmani (condition unknown in $\mathrm{H}$. romani and $C$. antiqua). It is noticeable that the posterior opening of the canalis cavernosus and the aditus canalis stapedio-temporalis are widely separated in these species (fig. 3B, C). In all remaining taxa (including panpleurodires and pancryptodires), the canalis cavernosus extends more posteriorly and the aditus canalis stapediotemporalis is located anterior to the level of the fenestra ovalis (fig. 3D, E). The two openings are significantly closer to one another and sometimes the aditus canalis stapedio-temporalis even opens directly in the roof of the posterior part of the canalis cavernosus. This evidence suggests a simultaneous forward migration of the aditus canalis stapedio-temporale and progressive lengthening of the canalis cavernosus in early turtles. Again, this observation gives credit to the phylogenetic pattern of Joyce [2007], as the morphology with closely located posterior opening of the canalis cavernosus and aditus canalis stapedio-temporalis would have to evolve independently in both panpleurodires and pancryptodires if $K$. aprix and E. waldmani were indeed basal pancryptodires as suggested by Gaffney et al. [2007] and Gaffney and Jenkins [2010].

The morphology of the processus interfenestralis of the opistothic also supports the idea that Kayentachelys aprix, Heckerochelys romani, Condorchelys antiqua and Eileanchelys waldmani are more basal than the dichotomy between panpleurodires and pancryptodires. In Proganochelys quenstedti (fig. 3A), Palaeochersis talampayensis, Australochelys africanus, but also in K. aprix (fig. 3B) and C. antiqua, the processus interfenestralis is a very robust structure far different from the thin, transverse sheet of bone known in modern turtles [e.g., Anquetin et al., 2009; Sterli and de la Fuente, 2010; see fig. 3D, E]. In contrast, the processus interfenestralis of $E$. waldmani (fig. $3 \mathrm{C}$ ) is more similar to that of extant turtles in being a transverse, flattened process [Anquetin, in press]. The condition in $H$. romani is difficult to assess from the published description of Sukhanov [2006], but it may have been comparable to that of E. waldmani. In these two species, the processus interfenestralis is still a large structure compared to the size of the skull. Again, if $K$. aprix and C. antiqua are considered to be basal pancryptodires as suggested by Gaffney and Jenkins [2010], then the modern morphology of the processus interfenestralis would be acquired by homoplasy in both panpleurodires and pancryptodires (fig. 3F). In contrast, following the pattern of relationships proposed by Joyce [2007], the typical processus interfenestralis of turtles appears only once along the phylogenetic stem of Testudines (fig. 3G).

All of the characters discussed above are cranial, and actually most of the turtle systematics is based solely on 
cranial characters. The evolution of the shell morphology in Mesozoic turtles needs to be reassessed thoroughly. Relatively few characters are used in phylogenetic analyses, but this is rather due to a lack of comprehensive revision than to an intrinsically poor informative potential of this kind of character. For the moment, it is difficult to discuss in detail the evolution of the shell in early turtles, with the exception of the number of peripheral plates and supramarginal scales in basalmost turtles [see Joyce, 2007; and references therein]. Yet, it is noteworthy that either nine neural or costal bones were described in several species of early turtles. Proganochelys quenstedti, Kayentachelys aprix, Condorchelys antiqua and Mongolochelys efremovi have been described as having nine costal bones [Gaffney et al., 1987; Gaffney, 1990; Khosatzky, 1997; Sukhanov, 2000; Sterli and de la Fuente, 2010]. Although no complete series is known, Eileanchelys waldmani apparently has eight costals like the majority of turtles [Anquetin, in press]. The number of costals (eight or nine) is uncertain in Heckerochelys romani [Sukhanov, 2006]. The presence of a ninth neural bone, or at least of an additional median bone posterior to the eighth neural, as been suggested for several early turtles: K. aprix (yet to be confirmed),
A
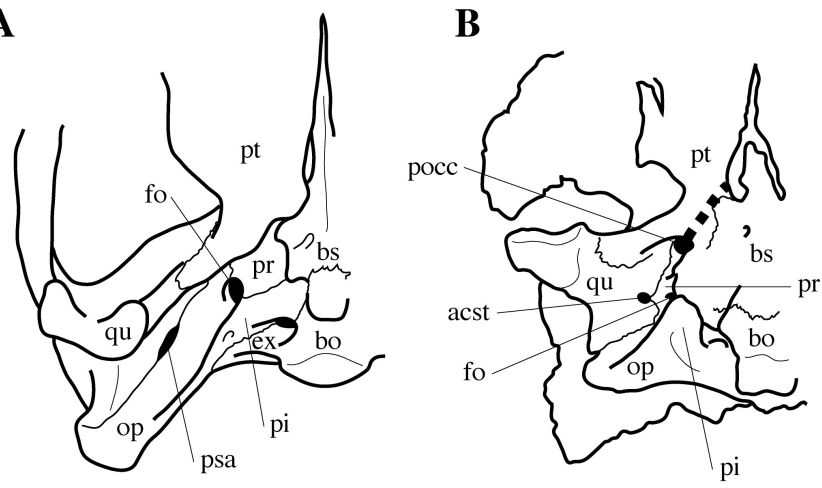

$\mathbf{F}$

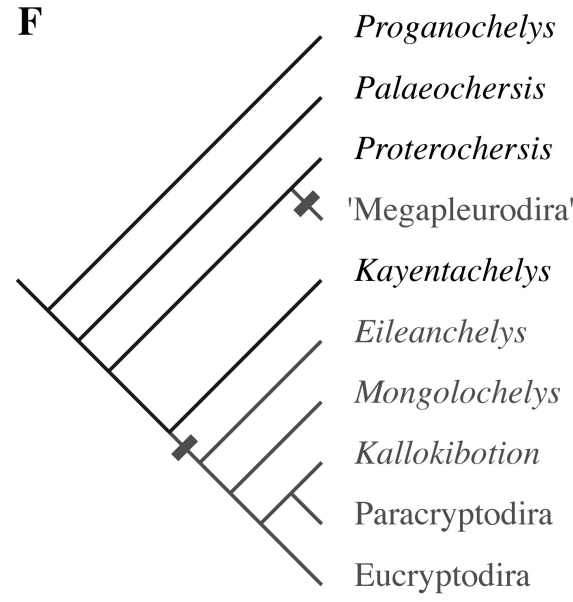

C
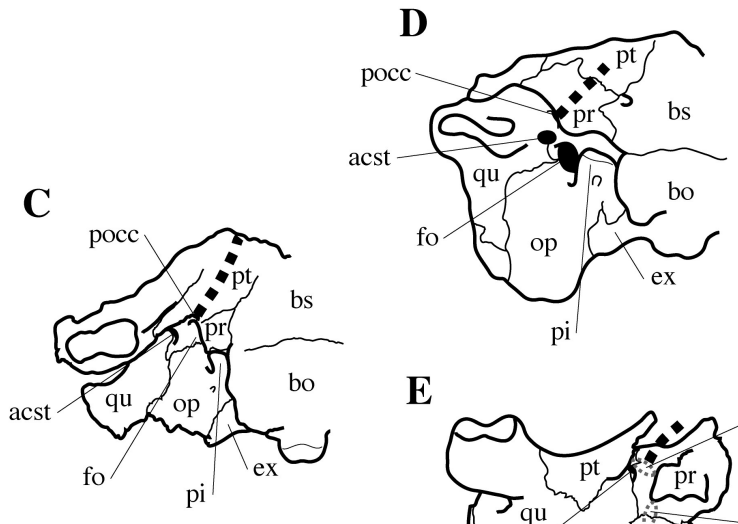

$\mathbf{E}$

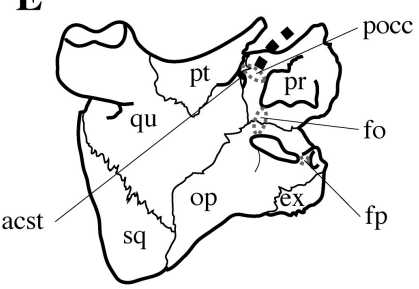

G

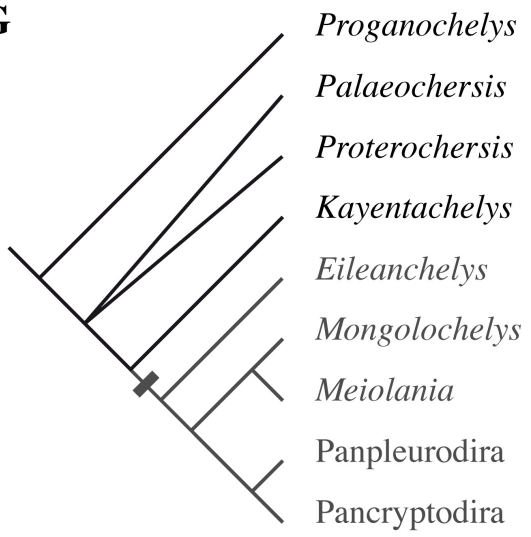

Figure 3 - Morphology of the cavum acustico-jugulare in selected turtles. A, Proganochelys quenstedti [modified from Gaffney, 1990]; B, Kayentachelys aprix [modified from Sterli and Joyce, 2007]; C, Eileanchelys waldmani [modified from Anquetin, in press]; D, Notoemys laticentralis [modified from Lapparent de Broin et al., 2007]; E, Chelydra serpentina [modified from Gaffney, 1979], pterygoid, basisphenoid and basioccipital removed; F, G, optimisation (DELTRAN) of the evolution of the processus interfenestralis of the opisthotic: F, simplified strict consensus tree, amended matrix of Gaffney et al. [2007]; G, simplified strict consensus tree, amended matrix of Joyce [2007]. Grey: processus interfenestralis with a modern morphology (see text). Dashed line: canalis cavernosus. Abbreviations: acst, aditus canalis stapedio-temporalis; bo, basioccipital; bs, basisphenoid; ex, exoccipital; fo, fenestra ovalis; fp, fenestra perilymphatica; op, opisthotic; pi, processus interfenestralis; pocc, posterior opening of the canalis cavernosus; pr, prootic; psa, passage for stapedial artery; pt, pterygoid; qu, quadrate; sq, squamosal. 
Indochelys spatulata, E. waldmani, M. efremovi, and maybe H. romani [Gaffney et al., 1987; Datta et al., 2000; Sukhanov, 2000; Anquetin, in press]. Although these issues need to be further investigated, preliminary observations relative to the number of costals and neurals favour the phylogenetic hypothesis of Joyce [2007] over that of Gaffney et al. [2007]. Indeed, if K. aprix, $C$. antiqua, $H$. romani, $E$. waldmani and $M$. efremovi are basal pancryptodires, then the typical turtle shell with eight neural and costal bones would have to evolve independently in both panpleurodires and pancryptodires.

\section{PALAEOECOLOGY}

The palaeoecology of early turtles has been debated intensively over the past two decades, because the purported ancestral ecology of the turtle lineage has been used as circumstantial evidence in discussions on the origin of turtles [see Joyce and Gauthier, 2004; Rieppel, 2008]. In other words, hypotheses placing the origin of turtles within parareptiles would be favoured if the former were ancestrally terrestrial [e.g., Reisz and Laurin, 1991; Laurin and Reisz, 1995; Lee, 1995, 1996, 1997; Joyce et al., 2009], whereas if turtles were ancestrally aquatic this would be more congruent with hypotheses relating them to sauropterygians [e.g., deBraga and Rieppel, 1997]. Although it is generally accepted that Testudines (crown-group turtles) are primitively aquatic, the habitat preference of stem turtles has remained controversial. Two recent studies, based on independent methods, have reinvigorated this debate [Joyce and Gauthier, 2004; Scheyer and Sander, 2007]. Forelimb proportions and extensive comparisons with extant taxa of known ecology led Joyce and Gauthier [2004] to conclude that Proganochelys quenstedti and Palaeochersis talampayensis were terrestrial animals and were not competent swimmers. This conclusion was supported by Scheyer and Sander [2007] who reported that the shell bone histology of Proganochelys quenstedti, Proterochersis robusta, Kayentachelys aprix and an indeterminate meiolaniid was more similar to that of terrestrial turtles than to that of aquatic forms. Both of these studies imply that the aquatic habitat preference, optimised to be basal for the crown-group, must have appeared along the turtle stem-lineage, somewhere in between $K$. aprix and Testudines. Inferring the palaeoecology of fossil turtles based solely on their obvious morphological traits has proved problematic [e.g., Joyce and Gauthier, 2004; see also below]. With the exception of fully marine species (presence of paddles, greatly reduced ossification of the shell, presence of a broad interorbital opening accommodating a large salt gland), the distinction between aquatic and terrestrial turtles may be difficult to identify on the basis of fossil material. Indeed, the boundary between terrestriality and aquatic habits is often blurred and many extant species actually live partly on land and partly underwater [e.g., Bonin et al., 2006]. This explains why discussions on the ecology of fossil turtles, especially the more basal ones, rarely reach a consensus.

Based on the presence of shell fontanelles and an inferred ligamentous shell bridge (i.e., the connexion between the carapace and the plastron), it has been proposed that Heckerochelys romani was an aquatic form [Danilov, 2005, p. 350]. However, neither of these characters is actually diagnostic of aquatic habits. For instance, a survey of extant species reveals that all extant terrestrial box turtles (i.e., Terrapene spp. and Cuora spp.) have a ligamentous bridge, whereas many aquatic turtles (e.g., most batagurids, deirochelydines, and all pleurodires) have an osseous bridge. Similarly, several extant terrestrial turtles (e.g., Manouria spp. and Malacochersis tornieri) have fontanelles, whereas many aquatic (e.g., most pleurodires) forms have a fully ossified shell. Fontanelles are also present in the shell of most species during development, so that only the persistence of fontanelles in adult individuals should be considered as potentially informative. Yet, stages of development in fossil species are not easy to determine, especially when, as in most reptiles, growth is extended more or less throughout life. For a given fossil species, when relatively few material is known, the presence of shell fontanelles may indicate that specimens at hand are juveniles. Eileanchelys waldmani provides a good example of this

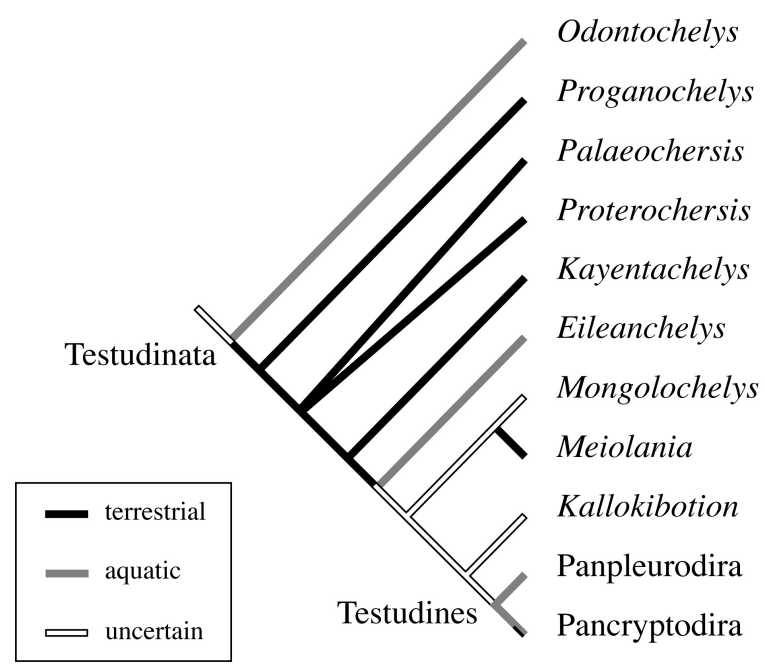

Figure 4 - Palaeoecology of early turtles. Phylogenetic relationships following Joyce [2007]. Relationships of Odontochelys and Eileanchelys according to Li et al. [2008] and Anquetin et al. [2009], respectively. Within Pancryptodira, some groups secondarily adapt to terrestrial habitats. 
phenomenon: only one of the four shells forming the paratype association has fontanelles and the concerned individual, only slightly smaller in size, is interpreted as a juvenile [Anquetin, in press]. Consequently, no positive evidence is currently available to conclude that Heckerochelys romani was aquatic and further investigations are needed.

Condorchelys antiqua was discovered in a series of lacustrine mudstones and limestones at Queso Rallado (Argentina) alongside terrestrial and aquatic vertebrates [Rauhut et al., 2002; Sterli and de la Fuente, 2010]. Rougier et al. [2007] describe the locality as system of littoral floodplain and small lakes. Turtles are among the most common vertebrates at this locality [O. W. M. Rauhut, pers. comm., 2008]. Given this relative abundance, it would be tempting to interpret $C$. antiqua as an aquatic form, but there are examples of terrestrial turtles found in number in freshwater deposits (e.g., Kayentachelys aprix). Furthermore, it is a fact that terrestrial vertebrates are most commonly found in aquatic deposits rather than in terrestrial sediments, owing to more favourable conditions of preservation. So, for the moment, the palaeoecology of $C$. antiqua is considered uncertain.

Anquetin et al. [2009] argued that Eileanchelys waldmani may be interpreted as one of the earliest known aquatic turtle (fig. 4). The Kilmaluag Formation at Cladach a'Ghlinne (type locality of E. waldmani) consists of alternations of calcareous mudstones, shales and occasional limestone horizons, which were formed in closed water systems that represent cycles of alternating low-salinity lagoons and freshwater floodplain lakes and pools [see Anquetin, in press]. Although the Cladach a'Ghlinne locality yields some articulated specimens [Evans et al., 2006], most of the material recovered from this site is scattered, fragmentary and has obviously suffered transport and/or other forms of disarticulation process. By contrast, many of the turtle specimens consist of articulated skulls, shells, limbs and vertebrae, indicating the absence or near absence of transport for them [Anquetin, in press]. Moreover, turtle remains represent some of the most abundant elements at the locality along with those of sharks and salamanders (i.e., aquatic forms), whereas remains of terrestrial vertebrates (e.g., lizards, dinosaurs, synapsids) are exceptionally rare. This taphonomic evidence (i.e., the abundance of the turtle remains, the numerical dominance of other aquatic taxa and the absence of transportation) suggests that $E$. waldmani was a denizen of these lagoons and lakes, rather than a terrestrial taxon that inhabited the inland areas adjacent to the lagoons and that was subsequently fossilised in the aquatic facies [Anquetin et al., 2009].
Odontochelys semitestacea, the most basal unambiguous stem turtle known to date, is another early turtle with supposed aquatic habits (fig. 4). Li et al. [2008] indicate that its forelimb proportions are comparable to those of extant turtles inhabiting stagnant or small bodies of water, as defined by Joyce and Gauthier [2004], but they conclude that this species lived in 'marginal areas of the sea or river deltas'. However, it should be noted that phalanges of the manus and pes of 0 . semitestacea are short and more similar to those of turtles with terrestrial habits; this matter should be further investigated. Li et al. [2008] consider that O. semitestacea represents the primitive ecology for turtles, whereas Reisz and Head [2008] think that its shell morphology is probably secondarily derived and that this species actually represents the earliest turtle radiation from terrestrial environments into marine habitats. Regardless of this debate, 0 . semitestacea and Eileanchelys waldmani are the only stem turtles which have been rather confidently interpreted as aquatic forms, whereas most other stem turtles are interpreted as being terrestrial (fig. 4). Because no direct relationship appears to exist between $O$. semitestacea and $E$. waldmani, the adaptation of the latter species to aquatic habitats must have evolved independently.

\section{CONCLUSIONS}

Recent discoveries from Middle Jurassic deposits have significantly improved our knowledge of turtles from that period of time and have partly filled the morphological gap that previously existed between Early and Late Jurassic forms. As shown herein, current cladistic analyses agree on the phylogenetic relationships of Heckerochelys romani, Condorchelys antiqua and Eileanchelys waldmani: these species are more derived than the Early Jurassic Kayentachelys aprix, but phylogenetically more basal than Mongolochelys efremovi, Kallokibotion bajazidi and meiolaniids (fig. 1). There are currently two opposing patterns of relationships proposed for early turtles. Following Gaffney et al. [2007], H. romani, C. antiqua and E. waldmani should be considered as basal pancryptodires, whereas, following Joyce [2007], these three species should be interpreted as stem turtles. Recently, the debate over these two competing hypotheses has focussed mainly on Kayentachelys aprix [Joyce, 2007; Sterli and Joyce, 2007; Gaffney and Jenkins, 2010].

The review presented herein shows that Heckerochelys romani, Condorchelys antiqua and Eileanchelys waldmani, by documenting yet unknown stages of the evolution of early turtles, provide further, independent support in favour of the hypothesis proposed by Joyce [2007]. If 
these three species are basal pancryptodires as hinted, but not discussed, by Gaffney and Jenkins [2010], then the following features have had to evolve independently in both panpleurodires and pancryptodires (see above for details): the typical dumbbell-shaped vomer with extensive contacts with surrounding bones; the closely located posterior opening of the canalis cavernosus and aditus canalis stapedio-temporalis (itself located anterior to the level of the fenestra ovalis); the modern morphology of the processus interfenestralis of the opisthotic; and maybe also the reduction of the number of costal and neural bones from nine to eight (further investigation is needed on this issue). This is in addition to characters already mentioned by Joyce [2007, pp. 57-61]. Hence, placing H. romani, C. antiqua, E. waldmani, and a fortiori $K$. aprix within pancryptodires is significantly less parsimonious than considering them as stem taxa when the entire anatomy is taken into account.

Habitat preference of fossil turtles can be difficult to assess, especially because morphological characters, such as shell fontanelles, ligamentous bridge, or even the flatness of the shell, are so little reliable. Recently, studies of forelimb proportions and shell bone histology have concluded that many stem turtles (i.e., Proganochelys quenstedti, Palaeochersis talampayensis, Proterochersis robusta, Kayentachelys aprix and meiolaniids) were terrestrial forms. However, it is now apparent that at least two stem turtles were probably aquatic: the Late Triassic Odontochelys semitestacea, either primitively or secondarily, and the Middle Jurassic Eileanchelys waldmani (fig. 4). Condorchelys antiqua and Heckerochelys romani, two recently described Middle Jurassic species, might as well turn out to be aquatic taxa, but further investigations are needed. These results demonstrate that stem turtles are ecologically more diverse than previously suspected. This is perhaps unsurprising as only about a dozen species of stem turtles are known representing a time span of approximately 60 m.y. (from the Late Triassic to the Middle Jurassic).

\section{Acknowledgements}

This paper is issued from a communication given at the 'Jurassic Environments and Faunas' Special Meeting of the Société Géologique de France, April 2010, Lyon (France). The organising and scientific committees, as well as the Société Géologique de France, are thanked for the opportunity to present and publish this study. Reviews by Walter Joyce and Julien Claude have improved the quality of this manuscript. Funding was provided by a postdoctoral grant from the Simone and Cino del Duca Fondation (2008 Fondation Prize to P. Janvier).

\section{References}

ANQUETIN J. (in press). - The anatomy of the basal turtle Eileanchelys waldmani from the Middle Jurassic of the Isle of Skye, Scotland. - Earth and Environmental Science Transactions of the Royal Society of Edinburgh.

ANQUETIN J., BARRETT P.M., JONES M.E.H., MOOREFAY S. \& EVANS S.E. (2009). - A new stem turtle from the Middle Jurassic of Scotland: new insights into the evolution and palaeoecology of basal turtles. Proceedings of the Royal Society of London, B, 276, 1658, 879-886.

ANQUETIN J. \& CLAUDE J. (2008). - Reassessment of the oldest British turtle: Protochelys from the Middle Jurassic Stonesfield Slate of Stonesfield, Oxfordshire, UK. Geodiversitas, 30, 2, 331-344.

BONIN F., DEVAUX B. \& DUPRÉ A. (2006). - Turtles of the world. - John Hopkins University Press, Baltimore. [Translated by P.C.H. Pritchard]

CEBRA-THOMAS J.A., TAN F., SISTLA S., ESTES E., BENDER G., KIM C., RICCIO P. \& GILBERT, S.F. (2005). - How the turtle forms its shell: a paracrine hypothesis of carapace formation. - Journal of Experimental Zoology, 304B, 558-569.

DANILOV I.G. (2005). - Die fossilen Schildkröten Europas. In: FRITZ U., Ed., Handbuch der Reptilien und Amphibien Europas, Band 3/IIIB. - Aula, Wiebelsheim, 329-441.

DANILOV I.G. \& PARHAM J.F. (2008). - A reassessment of some poorly known turtles from the Middle Jurassic of China, with comments on the antiquity of extant turtles. Journal of Vertebrate Paleontology, 28, 2, 306-318.

DATTA P.M., MANNA P., GHOSH S.C. \& DAS D.P. (2000). The first Jurassic turtle from India. - Palaeontology, 43, 1, 99-109.

deBRAGA M. \& RIEPPEL O. (1997). - Reptile phylogeny and the interrelationships of turtles. - Zoological Journal of the Linnean Society, 120, 281-354.

EVANS S.E., BARRETT P.M., HILTON J., BUTLER R.J., JONES M.E.H., LIANG M.-M., PARICH J.C., RAYFIELD E.J., SIGOGNEAU-RUSSELL, D. \& UNDERWOOD, C.J. (2006). The Middle Jurassic vertebrate assemblage of Skye, Scotland. In: BARRETT P.M. \& EVANS S.E., Eds., Ninth International Symposium on Mesozoic Terrestrial Ecosystems and Biota, Abstract and Proceedings. - The Natural History Museum, London, 36-39.

GAFFNEY E.S. (1972). - An illustrated glossary of turtle skull nomenclature. - American Museum Novitates, 2486, $1-33$. 
GAFFNEY E.S. (1975). - A phylogeny and classification of the higher categories of turtles. - Bulletin of the American Museum of Natural History, 155, 5, 389-436.

GAFFNEY E.S. (1979). - Comparative cranial morphology of recent and fossil turtles. - Bulletin of the American Museum of Natural History, 164, 65-375.

GAFFNEY E.S. (1990). - The comparative osteology of the Triassic turtle Proganochelys. - Bulletin of the American Museum of Natural History, 194, 1-263.

GAFFNEY E.S., HUTCHISON J.H., JENKINS F.A. \& MEEKER L.J. (1987). - Modern turtle origins: the oldest known cryptodire. - Science, 237, 289-291.

GAFFNEY E.S. \& JENKINS F.A. (2010). - The cranial morphology of Kayentachelys, an Early Jurassic cryptodire, and the early history of turtles. - Acta Zoologica, 91, 335-368.

GAFFNEY E.S. \& KITCHING J.W. (1995). - The morphology and relationships of Australochelys, an Early Jurassic turtle from South Africa. - American Museum Novitates, 3130, 1-29.

GAFFNEY E.S., RICH T.H., VICKERS-RICH P., CONSTANTINE A., VACCA R. \& KOOL L. (2007). Chubutemys, a new eucryptodiran turtle from the Early Cretaceous of Argentina, and the relationships of the Meiolaniidae. - American Museum Novitates, 3599, 1-35.

GILBERT S.F., LOREDO G.A., BRUKMAN A. \& BURKE A.C. (2001). - Morphogenesis of the turtle shell: the development of a novel structure in tetrapod evolution. Evolution \& Development, 3, 2, 47-58.

JOYCE W.G. (2007). - Phylogenetic relationships of Mesozoic turtles. - Bulletin of the Peabody Museum of Natural History, 48, 1, 3-102.

JOYCE W.G. \& GAUTHIER J.A. (2004). - Palaeoecology of Triassic stem turtles sheds new light on turtle origins. Proceedings of the Royal Society of London, B, 271, 1-5.

JOYCE W.G., JENKINS F.A. Jr. \& ROWE T. (2006). - The presence of cleithra in the basal turtle Kayentachelys aprix. In: DANILOV I.G. \& PARHAM J.F., Eds., Fossil Turtle Research, Vol. 1. - Russian Journal of Herpetology, 13(Suppl.), 93-103.

JOYCE W.G., LUCAS S.G., SCHEYER T.M., HECKERT A.B. \& HUNT A.P. (2009). - A thin-shelled reptile from the Late Triassic of North America and the origin of the turtle shell. - Proceedings of the Royal Society of London, B, 276, 507-513.

JOYCE W.G., PARHAM J.F. \& GAUTHIER J.A. (2004). Developing a protocol for the conversion of rank-based taxon names to phylogenetically defined clade names, as exemplified by turtles. - Journal of Paleontology, 78, 5, 989-1013.

KHOZATSKY L.I. (1997). - Big turtle of the Late Cretaceous of Mongolia. - Russian Journal of Herpetology, 4, 2, 148-154.

LAPPARENT DE BROIN F. de, DE LA FUENTE M.S. \& FERNANDEZ M.S. (2007). - Notoemys laticentralis (Chelonii, Pleurodira), Late Jurassic of Argentina: new examination of the anatomical structures and comparisons. - Revue de Paléobiologie, 26, 99-136.

LAURIN M. \& REISZ R.R. (1995). - A reevaluation of early amniote phylogeny. - Zoological Journal of the Linnean Society, 113, 165-223.

LEE M.S.Y. (1995). - Historical burden in systematics and the interrelationships of 'parareptiles'. - Biological Reviews of the Cambridge Philosophical Society, 70, 459-547.

LEE M.S.Y. (1996). - Correlated progression and the origin of turtles. - Nature, 379, 812-815.

LEE M.S.Y. (1997). - Pareiasaur phylogeny and the origin of turtles. - Zoological Journal of the Linnean Society, 120, 197-280.

LI C., WU X.-C., RIEPPEL O., WANG L.-T. \& ZHAO L.-J. (2008). - An ancestral turtle from the Late Triassic of southwestern China. - Nature, 456, 497-501.

LYSON T. \& GILBERT S.F. (2009). - Turtles all the way down: loggerheads at the root of the chelonian tree. Evolution \& Development, 11, 2, 133-135.

MADDISON D.R. \& MADDISON W.P. (2001). - MacClade. Version 4.01. - Sinauer Associates, Sunderland, MA.

MEYLAN P.A. (1987). - The phylogenetic relationships of soft-shelled turtles (family Trionychidae). - Bulletin of the American Museum of Natural History, 186, 1-101.

RABI M., JOYCE W.G. \& WINGS O. (2010). - A review of the Mesozoic turtles of the Junggar Basin (Xinjiang, Northwest China) and the paleobiogeography of Jurassic to Early Cretaceous Asian testudinates. Palaeobiodiversity and Palaeoenvironments, 90, 259-273.

RAUHUT O.W.M., MARTIN T., ORTIZ-JAUREGULZAR E. \& PUERTA P. (2002). - A Jurassic mammal from South America. - Nature, 416, 165-168.

REISZ R.R. \& HEAD J.J. (2008). - Turtle origins out to sea. - Nature, 456, 450-451.

REISZ R.R. \& LAURIN M. (1991). - Owenetta and the origin of turtle. - Nature, 349, 324-326.

RIEPPEL O. (2008). - The relationships of turtles within amniotes. In: WYNEKEN J., GODFREY M.H. \& BELS V., Eds., Biology of Turtles. - CRC Press, Boca Raton, FL, 345-353. 
ROUGIER G.W., de la FUENTE M.S. \& ARCUCCI A.B. (1995). - Late Triassic turtles from South America. Science, 268, 855-858.

ROUGIER G.W., GARRIDO A., GAETANO L., PUERTA P.F., CORBITT C. \& NOVACEK M.J. (2007). - First Jurassic triconodont from South America. - American Museum Novitates, 3580, 1-17.

SCHEYER T.M. \& ANQUETIN J. (2008). - Bone histology of the Middle Jurassic turtle shell remains from Kirtlington, Oxfordshire, England. - Lethaia, 41, 85-96.

SCHEYER T.M. \& SANDER P.M. (2007). - Shell bone histology indicates terrestrial palaeoecology of basal turtles. - Proceedings of the Royal Society of London, B, 274, 1885-1893.

SCHUMACHER G.H. (1954). - Beitrage zur Kiefermuskulatur der Schildkröten. - Wissenschaftliche Zeitschrift der Universität Greifswald, 3, 149-210.

STERLI J. (2008). - A new, nearly complete stem turtle from the Jurassic of South America with implications for turtle evolution. - Biology Letters, 4, 3, 286-289.

STERLI J. \& de la FUENTE M.S. (2010). - Anatomy of Condorchelys antiqua Sterli, 2008, and the origin of the modern jaw closure mechanism in turtles. - Journal of Vertebrate Paleontology, 30, 2, 351-366.

STERLI J., de la FUENTE M.S. \& ROUGIER G.W. (2007). Anatomy and relationships of Palaeochersis talampayensis, a Late Triassic turtle from Argentina. - Palaeontographica, Abteilung A, 281, 1-3, 1-61.

STERLI J. \& JOYCE W.G. (2007). - The cranial anatomy of the Early Jurassic turtle Kayentachelys aprix. - Acta Palaeontologica Polonica, 52, 2, 675-694.

SUKHANOV V.B. (2000). - Mesozoic turtles of Middle and Central Asia. In: BENTON M.J., SHISHKIN M.A., UNWIN D.M. \& KUROCHKIN E.N., Eds., The age of dinosaurs in Russia and Mongolia. - Cambridge University Press, Cambridge, 309-367.

SUKHANOV V.B. (2006). - An archaic turtle, Heckerochelys romani gen. et sp. nov., from the Middle Jurassic of Moscow region, Russia. In: DANILOV I.G. \& PARHAM J.F., Eds., Fossil Turtle Research, Vol. 1. - Russian Journal of Herpetology, 13(Suppl.), 112-118.

SWOFFORD D.L. (2002). - PAUP. Version 4.0b10. Sinauer Associates, Sunderland, MA.

TONG H., BUFFETAUT E. \& SUTEETHORN V. (2002). Middle Jurassic turtles from southern Thailand. Geological Magazine, 139, 6, 687-697.

YE X. (1994). - Fossil and recent turtles of China. Science Press, Beijing.
ZANGERL R. (1969). - The turtle shell, pp. 311-339. In: GANS C., BELLAIRS A. \& PARSONS T.S., Eds., Biology of the Reptilia, Volume 1. - Academic Press, London \& New York.

\section{Appendix 1: scorings for $H$. romani, C. antiqua and $E$. waldmani}

\section{Gaffney et al. [2007]}

Heckerochelys romani: 00101 101?? 0010000010 0?? 11 1?100 0?000 000111110111100 ?1??1 1?000 2????

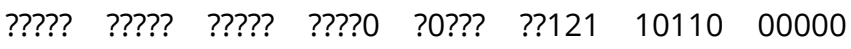
$00000 ?$

Condorchelys antiqua: ????? ????1 00100 00??? ????? ???00 0?000 0001111101 ?11?0 ?1101 1? 000 2??00 ??0?? ???0? ?00?? ?1??0 ????? ?002? ? 0??? ????? ????? ?

Eileanchelys waldmani: 00101 1011? $0 ? 100 \quad 00010$ 00011 ????0 0?000 0??11 1110111100 ?1101 1???0 2?? 00 ??00? ???0? ?00?? ???0? ????? ?1120 0?110 00000 000000

Missing data: Heckerochelys romani, 36.0\%; Condorchelys antiqua, 56.8\%; Eileanchelys waldmani, $32.4 \%$.

\section{Joyce [2007]}

Heckerochelys romani: 0??0? ???11 0???0 ????? ?1??? ? 1?1? 012?1 1?110 00000 00?1? 0?1?1 0???0 0??0? $00000 \quad 21011 \quad 101 ? 1 \quad 00000 \quad 00000 \quad 00010$ 00000 ????? ????? ??0?? ????1 ????0 ?--?? ????? ?

Condorchelys antiqua: ????? ????? 0???? ????? 1???? ????? 012?? 1?110 00?0? 00?1? 1?1?1 0???0 0??0? ?000? 2100? 00?01 00??? ???0? ????? ????? ?0?? 0 ????? ????? ????? ????0 ?--?? ????? ?

Eileanchelys waldmani: 00101 ?1111 0??10 000?0 ? 1010 01?1? 012?? 1??1? 0???? 0?01? 0?101 ?00?0 0??0? ?0000 21000 001?? 00000 ?000? ?001? 0000? ?0?? 0 ????? ????? ????1 ????0 ?--?? ????? ?

Missing data: Heckerochelys romani, 47.8\%; Condorchelys antiqua, 69.9\%; Eileanchelys waldmani, $45.6 \%$. 